BULLETIN Bulletin hispanique

HISPANIQUE Université Michel de Montaigne Bordeaux

$119-2 \mid 2017$

La Égloga renacentista en el Reino de Nápoles

\title{
Presentación
}

\section{Eugenia Fosalba y Gáldrick de la Torre Ávalos}

\section{OpenEdition}

\section{Journals}

Edición electrónica

URL: http://journals.openedition.org/bulletinhispanique/5017

DOI: 10.4000/bulletinhispanique.5017

ISSN: 1775-3821

\section{Editor}

Presses universitaires de Bordeaux

\section{Edición impresa}

Fecha de publicación: 1 diciembre 2017

Paginación: 417-426

ISBN: 979-10-300-0218-8

ISSN: 0007-4640

\section{Referencia electrónica}

Eugenia Fosalba y Gáldrick de la Torre Ávalos, «Presentación», Bulletin hispanique [En línea], 119-2 | 2017, Publicado el 28 noviembre 2017, consultado el 15 enero 2021. URL: http://

journals.openedition.org/bulletinhispanique/5017; DOI: https://doi.org/10.4000/bulletinhispanique. 5017

Este documento fue generado automáticamente el 15 enero 2021.

Tous droits réservés 


\title{
Presentación
}

\author{
Eugenia Fosalba y Gáldrick de la Torre Ávalos
}

1 Es un placer presentar este primer volumen del proyecto PRONAPOLI, compuesto por un amplio equipo internacional de historiadores y filólogos, estudiosos de Garcilaso y de la poesía del XVI, ya sea hispánica, italiana, o neolatina. Garcilaso es una figura capital de nuestras letras. A nadie se le oculta que la bibliografía acerca de su obra es absolutamente abrumadora. Por este mismo motivo, a estas alturas del siglo XXI, es muy posible que la mejor manera de seguir encontrando novedades, de seguir ahondando en su conocimiento, sea ponernos de acuerdo y colaborar una variedad de expertos, de entre los que deseo destacar a los miembros de la Università degli Studi di Napoli Federico II, cuya generosa acogida de la iniciativa ha resultado ser absolutamente fundamental. Garcilaso es un poeta cosmopolita, el conocimiento de cuya obra implica varios y no fáciles saberes, y es muy posible que a estas alturas solo su combinación esté capacitada para afrontar el reto de ver más allá, colaborando en equipo, corrigiéndonos, matizando, ofreciendo una confluencia de perspectivas entre la historia y las diversas filologías que están representadas en esta su primera publicación conjunta.

2 Puede que sorprenda que se insista una vez más en el influjo italiano en Garcilaso. Es cierto que su obra se ha estudiado desde hace muchos años y muy bien desde esa perspectiva. Las aportaciones en ese sentido son múltiples, como no podía de ser de otra manera. No obstante, los presupuestos básicos de los acercamientos a su vida y obra siguen muy afincados en la visión de los mismos que ofreció Rafael Lapesa en su admirable Trayectoria poética de Garcilaso (1948) hace ya más de sesenta años, con unas premisas que se han mantenido durante todo este tiempo como pilares de la explicación pedagógica de la evolución de la obra del toledano, y como guía básica, a su vez, de los acercamientos de los investigadores; aun así, hay muchos elementos que escapan al lecho de Procusto de dichos supuestos, con unas hipótesis tácitas de partida que es necesario poner en crisis, para revalidarlas si es preciso, pero más fundadamente, como se está intentando en los últimos años por parte de varios estudiosos reunidos en este proyecto. Urge incorporar el resultado de estas y otras, nuevas, investigaciones al discurso pedagógico e investigador acerca de la lírica renacentista y en concreto de Garcilaso de la Vega, cuya obra fundacional abrió la 
senda de la poesía española moderna; una breve y al mismo tiempo riquísima obra poética que precisa una perspectiva de análisis poliédrica, pluridisciplinar, enriquecida con nuevos datos. Se impone un acercamiento menos biografista, centrado en los supuestos amoríos del poeta, a favor, por el contrario, de un serio intento de reconstrucción de su biografía intelectual, todavía muy en la sombra, a pesar de la ingente cantidad de publicaciones que el gran poeta genera. La necesidad de desvelar en todos sus matices, en estrecha colaboración con especialistas en literatura napolitana en vulgar y también latina, la realidad literaria y cultural de los primeros años del virreinato de Pedro de Toledo coincide con el mismo movimiento en otros campos de la historiografía y del arte, como el proyecto europeo ENBACH (European Network for the Baroque Cultural Heritage), dentro del marco de Neapolitan Network.

3 El equipo de expertos aquí reunido se plantea un nuevo acercamiento a la obra de Garcilaso, proponiéndose una inmersión total en el contexto histórico, literario y cultural italiano, para sumergirnos muy especialmente en Nápoles: no interesa Garcilaso solo como mero receptor de una serie de influencias, sino más propiamente, como un poeta italiano, inmerso en ese ambiente e interactuando con los demás poetas del momento codo a codo, descubriendo en lengua castellana los caminos que se están empezando a abrir para otros poetas italianos amigos suyos que persiguen parejos propósitos.

4 Todo ello implica dos pasos fundamentales: por un lado, conocer de primera mano los textos de ese contexto italiano y la bibliografía que ha generado, para, si es preciso, revisar algunos matices de sus presupuestos en nuestros propios análisis (de los que este volumen sobre la égloga no es más que una primera muestra), y por el otro, difundir también entre la comunidad científica todo este material (fuentes primarias y secundarias) que nos va a permitir estos avances en la investigación del Reino de Nápoles durante los primeros cuarenta años del siglo XVI.

El propósito es pues acercar todo ese mundo de relaciones, jerarquías, textos, bibliotecas, y ponerlas al alcance del investigador para que este pueda romper con buena parte de los clichés que se han venido repitiendo, y se pueda por fin perfilar con mayor riqueza y abanico de matices una etapa decisiva de nuestra historia literaria. La experiencia investigadora de los miembros del proyecto acerca de este planteamiento de los estudios garcilasianos permite que tales presupuestos de partida superen la categoría de meras hipótesis, puesto que ya van siendo numerosos los resultados recogidos en este sentido. Se trata ahora de reunir nuestros esfuerzos, de potenciar una discusión entre nosotros que hace tiempo se dirime de forma las más de las veces espontánea, otras más articulada (como la que tuvo lugar en la Jornada de estudios «Si Garcilaso volviera...» La poesía española del Siglo de Oro entre imitación y reescritura, Università degli Studi Napoli Federico II, Nápoles, 25 de marzo de 2014, organizada por el Dr. Antonio Gargano), con el objeto de que los resultados puedan multiplicarse.

\section{La égloga renacentista en Nápoles}

Las muestras de églogas neolatinas habían proliferado en suelo italiano ya desde finales del XV en Ferrara, en Mantua, en Milán, en Florencia, en la Roma papal y, por supuesto, en Nápoles, con poetas como Pomponio Gaurico, Girolamo Angeriano, Giano Anisio, Giovanni Giovano Pontano y Iacopo Sannazaro, estos últimos con émulos en el norte de Italia tan destacados como Marcantonio Flaminio, Andrea Navagero y Girolamo 
Fracastoro. Hubo también una larga lista de vulgarizaciones del XV recogidas en Florencia por Antonio Miscomini en 1481, así como las incansables imitaciones también en vulgar de la Arcadia sannazariana, además de la tradición de las églogas destinadas a la representación que tuvieron como punto de partida el Orfeo (1478-1483) de Angelo Poliziano. En los primeros años del siglo XVI se dio también el contagio imparable de la moda bucólica al resto de Europa, convirtiéndose así el fenómeno pastoril en una auténtica epidemia. En el presente volumen se aplica la lente de aumento al fenómeno eglógico en el Reino de Nápoles, preferentemente en los años que dieron un contexto a las tres brillantes muestras que Garcilaso de la Vega legó a la posteridad. Se establecen distintos cortes sincrónicos, que confrontados resultan contrapuntísticos, sobre la evolución de dicho género literario, en el que nuestro autor adquirió la madurez como poeta. El volumen da comienzo con una aproximación histórica de la mano de Carlos José Hernando Sánchez, «El banquete de damas y caballeros: la corte galante de Carlos V en Nápoles» sobre el arraigo del fenómeno eglógico en el reino de la Nápoles imperial, auspiciado por la figura de Carlos V; una primera aproximación al fenómeno de la égloga que es brillante pórtico de todas las demás recogidas en el presente volumen, pues proporciona un rico marco acerca de las relaciones sociales y políticas del mundo de la corte en la Nápoles de 1530, centrándose sobre todo en la estancia imperial del invierno de 1535 , a propósito de las celebraciones que tuvieron lugar en la ciudad tras la victoria de la Jornada de Túnez, para analizar el momento y el despliegue cultural que propició desde el punto de vista político: el contraste de las relaciones de lo público y lo privado, el ceremonial que revistió la visita del Emperador en sus distintas manifestaciones artísticas y literarias, empezando por su entrada en la ciudad y sin dejar de atender a los distintos tipos de sociabilidad cortesana, de entre las que se destaca especialmente el banquete. Se desvela que tras tales acontecimientos que en apariencia servirían solo para reforzar el poder imperial, se ocultaban las tensiones políticas que alejaban a la nobleza napolitana de la autoridad del virrey de Nápoles Pedro de Toledo. Este trasfondo político, que Carlos Hernando sabe leer en la articulación de la fiesta napolitana y sus variadas manifestaciones culturales (de entre las que destaca la égloga), ilumina con pertinencia el resto del libro, donde se aborda dicho género poético desde perspectivas más exclusivamente literarias, pues la clave cortesana e histórica va a aflorar en no pocos de sus capítulos.

7 María Isabel Segarra Añón, en «De cómo el pastor Endimión mudó en la ninfa Enaria: del Canzoniere a las Methamorphosi de Cariteo», fija la atención sobre los últimos años de la vida de «il Cariteo» o Benet Garret; un periodo de la vida del escritor catalán del que la crítica se ha ocupado solo recientemente: atiende a la doble faceta de su trayectoria, política y literaria, común a sus compañeros de generación. Se ubica, por tanto, en el momento de la historia de Nápoles que va de la caída de la casa de Aragón a su nuevo dominio por parte de la monarquía española. En primer lugar, Segarra da cuenta del recorrido que siguió el Cariteo para situarse y adquirir una posición privilegiada en la corte del virrey Ramon Folch de Cardona; con ese objeto la autora analiza las referencias poéticas que aparecen en la obra del escritor dirigidas tanto a la figura del virrey como a Fernando el Católico. Una vez trazado el contexto, se adentra en el Endimione, un cancionero de corte petrarquista centrado en la relación del personaje mítico y la diosa Luna, donde Segarra descubre la progresión en el tratamiento del mito que lleva a identificar al poeta con el pastor Endimión y a su amada con el personaje de Luna, para detenerse finalmente en la deriva narrativa de la obra y el creciente interés por la épica a propósito del Libro de las Metamorphosi. 
Claudia Corfiati, en "Sulle egloghe neolatine di Girolamo Borgia: Gallicana», se ocupa del Girolamo Borgia poeta, en vez del historiador que siempre ha acaparado la atención de la crítica. Desde sus inicios, como miembro de la Academia pontaniana en Nápoles, aparece vinculado a la familia Ávalos-Colonna. No en balde, Borgia fue el preceptor del marqués de Pescara Francesco Ferrante, futuro condottiero italiano y marido de Vittoria Colonna. Los Carmina Lyrica et Heroica (Venetiis, Ex Typographia Iacobi Zattoni) son un compendio de poesías que Girolamo Borgia nieto edita y publica en el año 1666. Corfiati describe el contenido de la obra teniendo en cuenta aspectos tales como la estructura de la colección, el contexto histórico y la historia del texto. En este último punto se sirve de algunos testimonios del Seiscientos, entre los que cabe destacar, por su profundidad, el De illustribus scriptoribus de Bartolomeo Chioccarello, donde hay un apartado dedicado a las obras del escritor en el que se proporciona una reseña bibliográfica. Es ahí donde se especifica que Borgia compuso un total de doce églogas, de las cuales solo cuatro han sobrevivido, las que contiene la edición del sesenta y seis; es decir, las que integran el díptico de los Solatia aetatis calamitosae, las églogas Gallicana y Daphne, según aparecen tituladas en una parte de la tradición, además de las églogas Felix y Theogonia.

Tobia R. Toscano, en «Le egloghe latine di Giano Anisio, "amico" napoletano di Garcilaso», fija su atención en este autor tan olvidado de los últimos pontanianos. Giano Anisio se ubicaría cronológicamente entre la fase culminante del Reino de Nápoles, con la caída de la casa de Aragón, y la entrada del nuevo orden político de los imperiales. En esta primera parte, Toscano hace hincapié en algunos aspectos de su obra, como, por ejemplo, el hecho de que la publique al final de su vida. Existe un desajuste temporal entre el periodo de composición de los dos primeros libros, que sitúa la mayor parte de los poemas en aquel primer contexto histórico del reinado aragonés, y su fecha de publicación en 1531 y 1532; de tal modo que si estos dos primeros libros se vuelven hacia el pasado, los dos últimos, publicados respectivamente en 1533 y 1538, nos ofrecen, por el contrario, una mirada reciente. Toscano analiza el contenido de sendas publicaciones desde un punto de vista esencialmente político, por las referencias que aparecen en los poemas. Si los dos primeros libros nacen al amparo del cardenal Pompeo Colonna, en opinión del estudioso las referencias que aparecen en el tercer y el cuarto libro nos harían pensar en una deliberada voluntad de adhesión al programa político de Pedro de Toledo. Todas ellas vendrían a conformar una red de relaciones tejida por el poeta en torno a la figura del virrey en la que se hallarían algunas de las principales figuras que lo rodeaban, incluida la suya. En esta red de relaciones, encontraríamos, en el Variorum poematum liber de 1533, los epigramas dirigidos a Garcilaso, que por un error de la crítica se atribuían desde Mele a su hermano Cosme. Toscano descubre que ambas composiciones constituyen el primer testimonio poético de la llegada del toledano a Nápoles. Con motivo de la difusión en el reino del Orlando furioso, el autor enmarca la relación de Giano Anisio y de Garcilaso en el contexto cultural de auge de la literatura vulgar y el declive de la escritura latina, que es lo que, en opinión del autor, podría explicar que Garcilaso no escribiera epigramas en respuesta.

10 En «El grupo poético de Ischia y la adaptación al vulgar de la égloga piscatoria», Gáldrick de la Torre Ávalos parte de Fortunato Pintor, quien, en 1900, en una monografía dedicada a Bernardo Tasso, planteó la conocida hipótesis de que la adaptación al vulgar de la égloga piscatoria se gestó en Ischia en 1533, a instancias de la 
marquesa de Pescara. Pintor sugería la posibilidad de que este fuera el motivo de una supuesta justa poética, organizada por la poetisa, entre Berardino Rota y Bernardo Tasso. El estudioso relaciona esta hipótesis con el descubrimiento de Súzanne Thérault (1968) de la existencia en la isla de un cenáculo de escritores. El editor Scipione Ammirato afirmaba en su edición de las piscatorias de Rota ser este el inventor de la piscatoria en la lengua toscana, y añadía que estas tuvieron por ascoltatrice a Vittoria Colonna. En favor de tal argumento, se aportan algunos indicios que sitúan a Rota en el ámbito de las relaciones personales de la marquesa y que ponen de manifiesto también el interés de esta por las églogas piscatorias. Es aquí donde se recurre a la única carta que se conserva de la relación de ambos escritores y al volumen que Vittoria Colonna poseía del De partu Virginis; una edición de lujo de la princeps sannazariana que incluía también las églogas piscatorias. En la segunda y en la tercera parte, se analiza la obra de Bernardo Tasso y de Berardino Rota teniendo en cuenta el contexto cortesano de las composiciones piscatorias en las que aparece representada la marquesa.

11 Mercedes López Suárez, en «La égloga en vulgar o el bucolismo en su trayectoria de Siena a Nápoles», se interesa por los orígenes de la égloga vulgar y su difusión en Italia durante el siglo XV y principios del XVI. Empieza con una reflexión acerca de la manera en la que tradicionalmente se ha abordado el fenómeno, haciendo uso casi exclusivo de testimonios textuales (como, por ejemplo, las aportaciones de Carrara, Corti y de De Robertis), que ha servido para distinguir entre la égloga áulica o cortesana de Florencia y la rústica o realista de Siena, para reivindicar una mayor presencia de los elementos extratextuales; a saber: la forma de transmisión y de circulación de los textos, oral o escrita en sus dos modalidades, manuscrita e impresa; la influencia del sector editorial / comercial, «que incluye la actividad de los centros productores, la tipología de sus diferentes agentes (libreros, editores, tipógrafos, locales o itinerantes y ambulantes...)» y los formatos en que se difundió la égloga; y luego también la propia movilidad de los autores, determinada por razones políticas y culturales. La autora analiza en este sentido las relaciones entre los poetas y humanistas de Siena y Nápoles, teniendo en cuenta para ello sendos elementos textuales y extratextuales, para acabar ofreciendo así un comentario sobre la influencia de los pre-rozzi -el teatro popular sienés del siglo XV, que más tarde, en el XVI, se erige en academia- en la obra juvenil de Luigi Tansillo Il Vendemmiatore.

En «Ecos de la preceptiva minturniana en la concepción de las églogas de Garcilaso», Eugenia Fosalba aborda el estudio de la obra neoclásica del poeta toledano, y más en particular de sus églogas, desde la perspectiva de la teoría de la literatura. Tras intentar demostrar, en una publicación inmediatamente anterior y complementaria de la presente (2016), la composición temprana del De Poeta de Minturno (publicado por primera vez en 1559, pudo componerse, no obstante, entre 1525 , pasando por 1528 , tras la experiencia de Ischia, hasta aproximadamente 1533), la autora analiza el tratado en el contexto inmediato a la publicación de las Prose della volgar lingua de Bembo, frente a las que Minturno, en representación del tardo humanismo napolitano, adopta una toma de postura. Desde esta nueva perspectiva cronológica el De Poeta desvela, a su vez, la inspiración que dicho tratado pudo significar en la clasificación marcadamente genérica de la obra neoclásica de Garcilaso. La síntesis de géneros y estilos que implica la experimental égloga II, con su bucólica escénica, por momentos cómica, además de su hibridismo bucólico-épico, que no se resuelve en la mezcla o fusión de elementos (como se daría en el epilio), sino en una clara y definida yuxtaposición de los mismos, podría tener su origen en el complejo 
concepto que el de Traetto tenía de la épica, que comprendía la bucólica, participando esta última de rasgos propios de la comedia, lo que explicaría mejor que Garcilaso hubiera concebido su égloga como marco narrativo apropiado para el fragmento panegírico y heroico dedicado a profetizar la gloria de la Casa de Alba con la narración épica de sus gestas.

Por su parte, Antonio Gargano, en «El género bucólico en Nápoles: de la Arcadia de Sannazaro a la Égloga segunda de Garcilaso», se ocupa desde otro ángulo de la controvertida égloga II de Garcilaso, teniendo en cuenta que la relación con el modelo no solo supone la simple imitación, sino que, en todo caso, el ejercicio imitativo busca la superación del modelo en varios niveles: en el que implica la relación de la unidad y la coherencia, la combinación de los distintos géneros literarios y en general la concepción del género bucólico y el valor ideológico y contextual de la obra. Al caer el reinado aragonés, y de ello da cuenta el poeta en el epílogo A la sampogna, el género bucólico habría perdido la posibilidad de celebrar a grandes príncipes; de manera que, si la obra, todavía en consonancia con la bucólica cuatrocentista, promete, mediante la figura del Carino sannazariano, cantar con más alto estilo los amores de los faunos y de las ninfas por parte del pastor Sincero, al final de la prosa VII de la Arcadia, esta promesa se habría visto truncada con la caída de la casa de Aragón. Garcilaso habría intentado la contaminación del género épico con el bucólico por el hecho de que era una figura vinculada al imperio; en su caso, sí habría hallado razones por las que celebrar con su zampoña a los nuevos gobernantes. Finalmente, Gargano apunta en la égloga II la celebración de un nuevo orden político, con la hipótesis de tres tiempos, el mítico, el histórico y el profético que Garcilaso habría querido conjugar en su obra de manera similar a la cuarta bucólica de Virgilio; en una historia que nos llevaría de la pasión de los «puerili anni» de Albanio y Camila, al tiempo de la historia y la edad adulta, marcado por la insatisfacción del deseo, y su superación, hacia el tiempo profético que materializa la segunda parte de la obra.

Si bien la crítica ha dedicado muchos ensayos al intento de dilucidar qué bella dama se ocultaba tras de la persona de Galatea en su égloga I, ha mostrado mucho menos interés por saber qué implicaba la elección de este y no otro nombre. Se suelen aducir los nombres de Teócrito, de Virgilio y de Ovidio, a veces el de Sannazaro, y Galatea se interpreta como símbolo de la perfección de la mujer insensible, pero no se indaga en lo que esta elección pudo significar para Garcilaso. La contribución de Roland Béhar en «Galatea o la idea de la belleza garcilasiana» trata de demostrar cómo esta elección cobra todo su sentido si se la considera desde la perspectiva de la poesía napolitana de su tiempo, donde se observan múltiples reescrituras de Teócrito y de Virgilio. La primera y más significativa es sin duda la de Sannazaro, que se hace eco de la invención por parte de Rafael, en los mismos años, de la imagen ideal de Galatea en Villa Farnesina. Pontano, junto con Poliziano y, después, Pietro Bembo, había resuscitado ya el interés por Galatea a finales del Quattrocento; no obstante, le corresponde a Sannazaro el hacer de ella la figura central de una de sus églogas piscatorias y de volver a situarla en el centro del interés de sus imitadores y competidores poéticos. Entre ellos, Antonio Tilesio y Giano Anisio, en Nápoles, y Nicolas Bourbon, en Francia, presentan los modelos neolatinos que más se acercan a lo que Garcilaso desarrolla, y pueden haberle inspirado sus versos. En volgare, Luca Valenziano y, después de Garcilaso, Luigi Tansillo, ofrecen otros términos de comparación, que sugieren con más fuerza la necesidad de interpretar la égloga I desde una perspectiva cortesana. La labor de la imitatio garcilasiana carece, en efecto, de sentido si no se inscribe en el 
funcionamiento de la corte virreinal de don Pedro de Toledo, nutrida de la doctrina del Cortesano de Castiglione, donde es preciso esconder bajo el velo del mito y de la ficción poética lo que la secretezza impide expresar abiertamente. Aunque no se haya descifrado aún, la elección del nombre de Galatea no supone tanto una alusión a la biografía personal del poeta cuanto a la de sus mecenas.

Por su parte, Flavia Gherardi, en "Veder tronca la speme e "l desir morto"». I due pellegrini de Tansillo en la urdimbre estilístico-temática de la égloga I de Garcilaso», aborda la relación intertextual que se establece entre la égloga I de Garcilaso e I due pellegrini de Tansillo, con un breve comentario de la bibliografía que ha encarado la cuestión. Se hace hincapié en el hecho de que la bibliografía se ha dedicado simplemente a señalar la influencia de I due pellegrini sobre la obra de Garcilaso, en el mejor de los casos analizándola solo superficialmente (González Miguel), pero nunca en profundidad. Por ello la autora se propone ahondar en la cuestión y anotar las confluencias en los distintos pasajes de uno y otro poema: rescata algunos de los aspectos puestos de relieve por parte de la bibliografía -los más generales-: los parecidos temáticos o argumentales, textuales y estructurales, y ahonda en ellos en busca de la huella concreta, detalles útiles para integrar en el discurso crítico de la égloga I.

En «La Égloga Nice de Juan de la Vega» Maria D’Agostino aborda la desconocida figura y obra de Juan de la Vega: a partir de las noticias extraídas de su cancionero, los Versos de Juan de la Vega, se formula la hipótesis de que puede tratarse del mismo personaje que aparece citado en el íncipit de un privilegio: el soldado español Juan de la Vega, que llegó a Nápoles en tiempos de Carlos V -probablemente, en 1541- y que participó, entre otras, en la batalla de Siena. Tras una descripción formal del ejemplar, se da cuenta de algunos aspectos relacionados con su contenido: su carácter plurilingüe, que la fábula vincula a la tradición de los tempio di ritratti; también se atiende a la estructura y organización del poemario; su variedad métrica y temática; la datación de los poemas y también el contexto histórico. Una vez caracterizado el conjunto de la colección, el artículo comenta la Égloga Nice, aspectos como su estructura y circunstancias de gestación, para ofrecer después su edición.

17 Finalmente, María de las Nieves Muñiz, en «El sueño y el llanto: caminos de la bucólica entre Italia y España (De Sannazaro y Garcilaso a Cervantes)», analiza las expresiones literarias del sueño y el llanto desde la Antigüedad al Renacimiento y los poetas del Siglo de Oro español.

\section{Comité científico}

Dr. Juan Francisco Alcina (Universitat Rovira i Virgili)

Dra. Carmen Codoñer (Universidad de Salamanca)

Dr. Enric Mallorquí-Ruscalleda (California State University-Fullerton)

Dra. Ines Ravasini (Università di Bari)

Dra. Encarnación Sánchez (Università degli Studi di Napoli L'Orientale) 


\section{AUTORES}

\section{EUGENIA FOSALBA}

Universitat de Girona

GÁLDRICK DE LA TORRE ÁVALOS

Universitat de Girona 